\title{
A nationwide survey on the use of heated humidified high flow oxygen therapy on the paediatric wards in the UK: current practice and research priorities
}

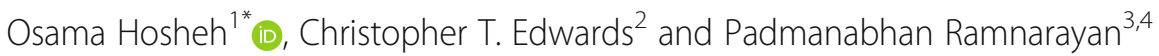

\begin{abstract}
Background: Heated Humidified High Flow Nasal Cannula Oxygen Therapy (HHFNC) is increasingly used on the paediatric wards and High Dependency Units (HDU) for different types of pathologies and different age groups. We aimed to describe current practice related to the use of HHFNC on the paediatric wards and HDUs, weaning practices and preferred outcome measures for future research.

Methods: We carried out a cross-sectional online survey of UK paediatric consultants or their delegates working on the paediatric wards. Descriptive analysis of their geographical, and organizational characteristics, their specialties, and their level of experience was investigated. Reasons for HHFNC initiation, weaning criteria, patients' characteristics and their primary pathologies were also analysed.

Results: Participation of 218 paediatricians from 81 hospitals (Median: 2.7, Range: 1-11) was registered. HHFNC was provided in most of the surveyed hospitals $(93 \%, 75 / 81)$. A High Dependency Unit (HDU) was available in 47 hospitals (58\%); less than a third of those have a dedicated paediatrician. Decisions around HHFNC were made solely by paediatricians in (75\%) of the cases, mostly at hospitals with no HDU compared to those with dedicated HDUs (70.3\% VS 36.6, 95\%Cl:22.6-50.4\%, $P<.001)$. HHFNC was reported by nearly two-thirds $(68 \%)$ of the practitioners who used it on the wards to be as effective or superior to CPAP (Continuous Positive Airway Pressure) with fewer complications. Failure rate while on HHFNC was identified as the most important outcome measure in any future research followed by the length of need for HHFNC support (37.1, and 28\% respectively).
\end{abstract}

Conclusion: This survey showed support for developing paediatric-specific national guidance on the use of HHFNC on the wards. Our list of defined research priorities may help guide further collaborative research efforts in this field.

Keywords: High flow nasal cannula, Paediatrics, Children, Oxygen therapy, Adjunctive therapy

\section{Background}

Heated Humidified High Flow Nasal Cannula Oxygen Therapy (HHFNC) has become increasingly popular as

\footnotetext{
* Correspondence: drosama@hotmail.com

'Paediatric Intensive Care Unit, Birmingham Children's Hospital, Birmingham Women's and Children's Hospital Foundation Trust, Steelhouse Lane, Birmingham B4 6NH, UK

Full list of author information is available at the end of the article
}

an option for non-invasive respiratory support of infants and children in critical care [1]. More recently, HHFNC has also been introduced into paediatric wards in the United Kingdom (UK), mainly for the management of bronchiolitis [2], and although high-quality evidence has begun to emerge on the clinical effectiveness of HHFNC compared to standard low flow oxygen therapy [3], other trials that compared it with CPAP were primarily

(c) The Author(s). 2020 Open Access This article is licensed under a Creative Commons Attribution 4.0 International License, which permits use, sharing, adaptation, distribution and reproduction in any medium or format, as long as you give appropriate credit to the original author(s) and the source, provide a link to the Creative Commons licence, and indicate if changes were made. The images or other third party material in this article are included in the article's Creative Commons licence, unless indicated otherwise in a credit line to the material. If material is not included in the article's Creative Commons licence and your intended use is not permitted by statutory regulation or exceeds the permitted use, you will need to obtain permission directly from the copyright holder. To view a copy of this licence, visit http://creativecommons.org/licenses/by/4.0/. The Creative Commons Public Domain Dedication waiver (http://creativecommons.org/publicdomain/zero/1.0/) applies to the data made available in this article, unless otherwise stated in a credit line to the data. 
bronchiolitis-focused [4] with debatable interpretations $[1,5]$. The current use of HHFNC in infants and children, therefore, is still largely based on individual experience with a clear lack of national and international guidance.

The primary mechanism of action for HHFNC is not well known but has many theoretical ones by which it reduces the work of breathing and improves efficiency of ventilation $[6,7]$ by washing out the nasopharyngeal dead space leading to improved alveolar ventilation, reduction in the inspiratory resistance associated with the nasopharynx, improvement in conductance and pulmonary compliance by supplying adequately warmed and humidified gas and provision of positive distending pressure for lung recruitment although the latest is variable $[1,8]$. Optimal starting flow rate, strategies for weaning, feeding, and use of adjunctive therapy such as nebuliser therapy are some of the unanswered questions while applying HHFNC [9]. Moreover, its use for diseases other than bronchiolitis [10], and during paediatric retrieval is still being explored [11]. Regarding flow rates, there are no national or international guidelines in infants or children yet $[12,13]$ and although a range of $1.5-2 \mathrm{~L} / \mathrm{kg} /$ min has widely been adopted in current paediatric practice and previous clinical studies, we expect that there is a spectrum of maximum HHFNC flow rates that are currently trialled on our paediatric wards. In addition, there are no solid weaning protocols for HHFNC which may prolong the length of hospital stay $[10,14,15]$. There is also a limited number of observational studies describing the supportive care of patients receiving HHFNC (i.e. nasogastric (NGT) or nasojejunal tubes (NJT) VS. oral feeding, aerosol delivery techniques for inhalational drug delivery, and use of sedation while on HHFNC) $[9,10]$.

Because of the uncertainty surrounding the use of HHFNC in paediatric practice, we aimed to survey the UK paediatricians with the following objectives: a) to describe the current practice related to the use of HHFNC on the paediatric wards and HDUs for different age groups and different pathologies; b) to describe weaning practices and supportive care during HHFNC, and c) to define research priorities and preferred outcome measures for any future randomised controlled trials.

\section{Methods}

We carried out a cross-sectional online survey of UK paediatric consultants using the Online Survey Software (formerly BOS, onlinesurveys.ac.uk, Jisc software, UK) to elicit their responses regarding practice related to HHFNC and their perceptions regarding research priorities. The survey covered four main domains:

1- general information about the respondents,
2- their wards and their patients' characteristics including their primary illnesses,

3- information about the use of HHFNC in practice including responses to two case scenarios, comparison with both low flow oxygen therapy (LF) and CPAP.

4- finally, the respondents' opinion of future trials on HHFNC and the key priorities in any further research.

An initial version of the survey was piloted (by 7 paediatric consultants) in three regions across the UK and these responses were used to inform the final questionnaire used in this survey (Additional file 1, Survey questionnaire). Questions were directed to paediatric consultants (or their delegates such as a senior registrar or a nurse practitioner) who spend more than $50 \%$ of their clinical time in their specialty within the UK. Completion of the survey was voluntary, and consent was not required. The survey link was initially distributed by the Royal College of Paediatrics and Child Health (RCPCH) e-bulletin, and by the British Paediatric Respiratory Society (BPRS) through their mailing lists. We also requested the 12 regional Paediatric Intensive Care retrieval services to forward the survey link to the acute hospitals in their geographical area. Phone calls to the paediatric wards and HDUs were also made where their regions were noticed to be underrepresented in the survey. Data were collected between September 2018 and June 2019.

Data about the number of hospitals with paediatric services in the UK were obtained from the RCPCH Medical Force Census 2015 [16]. The definition of HDU is detailed in (High Dependency Care for Children, Time to Move On, RCPCH, October 2014). High Dependency Care (HDC) describes the child who is critically ill requiring enhanced observation, monitoring and intervention but also is used to describe the child who is not critically ill but requires additional nursing care for other reasons [17].

We primarily used the respondent as the unit of analysis other than for questions relating to hospital characteristics. Results are reported as proportions and/or means as appropriate. Significance testing for differences in proportions was performed using the chi-square test and for differences in means for normally distributed data using the Student t-test. Data analyses were performed using Stata v16 (Stata Corporation, College Station, USA) and Microsoft Excel 2016 (Microsoft Corporation, USA).

\section{Results}

A total of 218 respondents participated in the survey, representing 81 hospitals across the 12 regions in the UK (total registered hospitals with acute paediatric 


\begin{tabular}{|l|r|}
\hline Region & Responses \\
\hline West Midlands & 46 \\
\hline Yorkshire and the Humber & 35 \\
\hline London & 33 \\
\hline South West & 23 \\
\hline East Midlands & 21 \\
\hline North West & 13 \\
\hline Scotland & 13 \\
\hline South East & 10 \\
\hline Northern Ireland & 8 \\
\hline East of England & 6 \\
\hline Wales & 6 \\
\hline North East & 4 \\
\hline
\end{tabular}

Fig. 1 Respondents per region

services in Great Britain and Northern Ireland as per the RCPCH Medical Force Census 2015 were 171) (Fig. 1). The median response was 2.7 (range: 1-11) per hospital. Majority of the participants were paediatric consultants $(213 / 218,97.7 \%)$ with a wide range of clinical experience in their field (Table 1).

Forty-seven hospitals $(58 \%)$ had dedicated HDUs, with more than a third $(19 / 47,40 \%)$ were with an on-site Paediatric Intensive Care support (PICU). Twelve HDUs $(12 / 19,63 \%)$ were solely managed by the intensive care team and only seven HDUs $(7 / 47 \approx 15 \%)$ had a dedicated paediatrician. The majority of HDUs provided all types of non-invasive ventilation (including Bilevel Positive pressure ventilation, BLPAP) and long-term invasive ventilation (LTV) (43/47, 91.5\%). Table 2 represents patient categories that were generally managed on hospital wards.

\section{Use of HHFNC}

Respondents reported using HHFNC in a variety of illnesses on their wards particularly where HDU and intensive care facilities are not readily available (such as
Table 1 Characteristics of the respondents by specialty and experience

\begin{tabular}{|c|c|c|c|}
\hline & $\begin{array}{l}\text { Working in hospitals } \\
\text { with } \\
\text { HDU }(n=164, \%)^{c}\end{array}$ & $\begin{array}{l}\text { Working in } \\
\text { hospitals with no } \\
\text { HDU }(n=54, \%)^{c}\end{array}$ & $p$-value \\
\hline \multicolumn{4}{|c|}{ Main Specialty (> 50\% clinical time) } \\
\hline $\begin{array}{l}\text { General } \\
\text { Paediatrics }\end{array}$ & $119(72.6)$ & $48(89)$ & .0137 \\
\hline PEM $^{a}$ & $5(3)$ & $1(1.8)$ & .63 \\
\hline $\mathrm{PICM}^{\mathrm{b}}$ & $4(2.4)$ & 0 & \\
\hline Cardiology & $5(3)$ & $1(1.8)$ & .63 \\
\hline Respiratory & $25(15.2)$ & $1(1.8)$ & .008 \\
\hline Neonates & $2(1.2)$ & $2(3.7)$ & .23 \\
\hline $\begin{array}{l}\text { Others (HDU } \\
\text { consultant, } \\
\text { nurse } \\
\text { practitioner) }\end{array}$ & $4(2.4)$ & $1(1.8)$ & .79 \\
\hline \multicolumn{4}{|c|}{ Clinical Experience } \\
\hline$<1$ Year & $10(6)$ & $2(3.7)$ & .5 \\
\hline $1-5$ Years & $60(36.6)$ & $20(37)$ & .95 \\
\hline $6-10$ Years & $54(32.9)$ & $14(8.5)$ & .0005 \\
\hline$>10$ Years & $40(24.4)$ & $18(10.9)$ & .035 \\
\hline
\end{tabular}

${ }^{\mathrm{a} P a e d i a t r i c ~ E m e r g e n c y ~ M e d i c i n e, ~}{ }^{\mathrm{b}}$ Paediatric Intensive Care Medicine.

${ }^{\mathrm{C}}$ Rounded percentages where possible

respiratory, cardiac, and neuromuscular diseases). Respiratory diseases collectively accounted for more than $75 \%$ of the reasons to start HHFNC (Fig. 2).

The most common clinical indication for HHFNC initiation was hypoxia (oxygen saturation $<92 \%$ ) not responding to LF (defined as administration of oxygen of $\leq 4 \mathrm{~L} / \mathrm{min}$ via nasal cannula) (Fig. 3).

Paediatric wards were the primary location to start HHFNC according to the majority of respondents (167/ $218,76.6 \%)$. Other locations such as the emergency department were also considered an option when a ward bed was not immediately available. Six respondents

Table 2 Categories of paediatric patients admitted to the wards/HDU in 81 hospitals

\begin{tabular}{lll}
\hline $\begin{array}{l}\text { Patient Categories on the Ward/ } \\
\text { HDU }\end{array}$ & $\begin{array}{l}\text { Respondent }\left(\mathrm{n}^{\mathrm{a}},\right. \\
\%)\end{array}$ & $\begin{array}{l}\text { Hospital } \\
\%)\end{array}$ \\
\hline Medical & $\mathrm{n}^{\mathrm{a}}$, \\
Respiratory & $207(95)$ & $78(96)$ \\
Surgical & $188(86.2)$ & $76(94)$ \\
Neonates < 28 days & $162(74.3)$ & $65(80)$ \\
Neurology/Neurosurgery & $150(68.8)$ & $61(75)$ \\
Trauma & $126(57.8)$ & $51(63)$ \\
Cardiac/Cardiac Surgical & $121(55.5)$ & $49(60)$ \\
Others (ENT, Plastics, Burns, Gastro) & $18(8.3)$ & $26(32)$ \\
\hline
\end{tabular}

Based on 218 responses, and 81 hospitals 


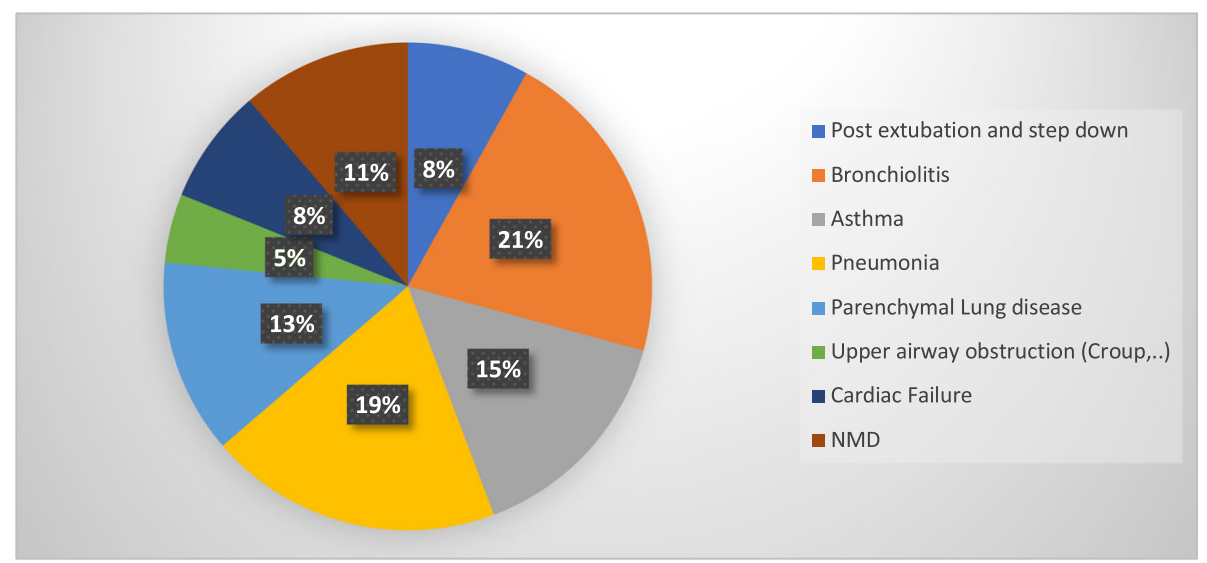

Fig. 2 Initiation and modification of HHFNC (NMD: Neuromuscular diseases)

representing 5 cardiology wards from 4 different regions reported using HHFNC for cardiac patients with different pathologies (pre- and post-heart surgery). Most respiratory physicians in this survey $(24 / 26,92 \%)$ considered their respiratory wards as HDU-acuity level therefore HHFNC became a standard therapy on these wards. HDU and PICU were the primary locations to start HHFNC therapy in $8 / 218$ responses (3.6\%).

Starting HHFNC therapy on the ward was overall a paediatric team-led decision, and similarly modification and weaning off HHFNC (paediatric consultant, respiratory consultant, registrar, senior nurse, or nurse practitioner) particularly in hospitals with no HDU compared to hospitals with dedicated HDUs $\{24 / 34$ (70.3\%) VS $17 /$ 47 (36.6\%), 95\%CI: 22.6-50.4\%, P: .002\}.

Relevant guidance on HHFNC was more available in hospitals with HDUs compared to hospitals with no
HDU \{36/47, (77\%) VS 17/34 (50\%), 95\%CI: 5.9-45.6, P: $.012\}$ (Table 3):

For a better understanding of how a decision around starting and modifying HHFNC on the ward is made, we presented 2 clinical vignettes in our survey in terms of the application of HHFNC on the wards based on age and weight: findings to these scenarios are summarized in (Fig. 4). Clinical parameters by which the respondents assessed failure of HHFNC included significant work of breathing, worsening respiratory acidosis, apnoea needing stimulation, significant tachypnoea and tachycardia, deterioration on the local assessment scores (i.e. PEWS).

Weaning off HHFNC was managed variably by respondents with the majority opting to wean the $\mathrm{FiO} 2$ to a certain value (most commonly 0.40 , indicated by $62.2 \%$ of respondents) and then gradually weaning the flow rate afterwards ( $75.7 \%$ of respondents).

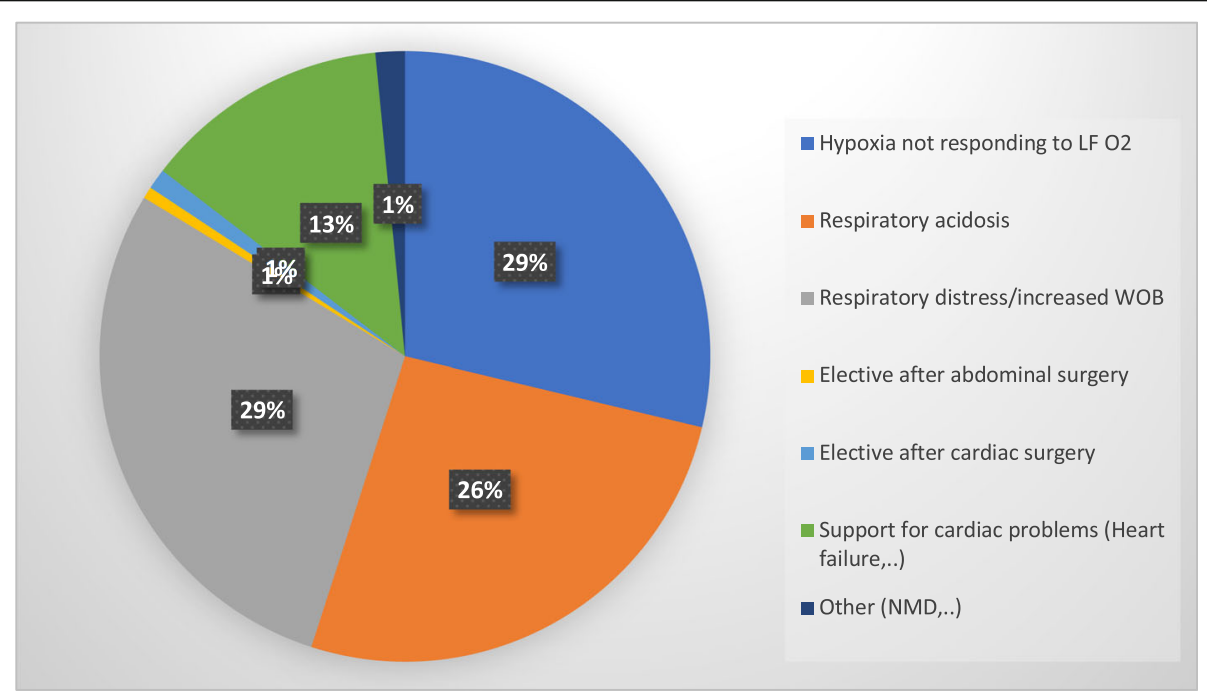

Fig. 3 Indications for HHFNC on the ward 
Table 3 Responses in terms of HHFNC guidelines, options for respiratory support and application of supportive therapy on the wards

\begin{tabular}{|c|c|c|c|}
\hline & $\begin{array}{l}\text { Working in hospitals with HDU } \\
(n=164, \%)\end{array}$ & $\begin{array}{l}\text { Working in hospitals with no HDU } \\
(n=54, \%)\end{array}$ & $p$-value \\
\hline Decisions to start HHFNC by Paediatricians, n (\%) & $60(36.6)$ & $38(70.3)$ & .0001 \\
\hline Availability of guidelines for HHFNC, $n(\%)$ & $127(77.4)$ & $27(50)$ & .0001 \\
\hline \multicolumn{4}{|l|}{ Proportion of patients using HHFNC on the ward, $\mathrm{n}(\%)$} \\
\hline$<1 \%$ & $21(12.8)$ & $14(6)$ & .17 \\
\hline $1-5 \%$ & $47(28.6)$ & $22(40.7)$ & .12 \\
\hline $6-10 \%$ & $34(20.7)$ & $1(1.8)$ & .001 \\
\hline $11-20 \%$ & $12(7.3)$ & $1(1.8)$ & .14 \\
\hline$>20 \%$ & $2(1.2)$ & $9(16.7)$ & .0001 \\
\hline HHFNC not used on my ward & $9(5.5)$ & $6(11.1)$ & .16 \\
\hline Don't know & $39(23.7)$ & $1(1.8)$ & .0001 \\
\hline \multicolumn{4}{|c|}{ Available options for respiratory support on the ward (including HDU), n (\%) } \\
\hline Low Flow O2 & $164(100)$ & $54(100)$ & N/A \\
\hline HHFNC & $155(95)$ & $47(87)$ & .067 \\
\hline CPAP and/or BLPAP & $152(92.7)^{a}$ & $15(27.7)^{\mathrm{b}}$ & .05 \\
\hline Established LTV & $111(67.7)^{c}$ & 0 & \\
\hline \multicolumn{4}{|l|}{ Supportive Therapy } \\
\hline \multicolumn{4}{|l|}{ Aerosol therapy, n (\%) } \\
\hline MDI therapy without stopping HHFNC & $13(7.9)$ & $4(7.4)$ & NS \\
\hline MDI therapy, HHFNC is temporarily stopped & $12(7.3)$ & $4(7.4)$ & NS \\
\hline Nebulised therapy without stopping HHFNC & $101(61.6)$ & $31(57.4)$ & .58 \\
\hline Nebulised therapy, HHFNC is temporarily stopped & $5(3)$ & 0 & \\
\hline I don't know & $15(9.1)$ & $7(12.9)$ & .40 \\
\hline \multicolumn{4}{|l|}{ NGT insertion, n (\%) } \\
\hline Always & $26(15.8)$ & $6(11.1)$ & .38 \\
\hline Most of the times & $84(51.2)$ & $22(40.7)$ & .22 \\
\hline Sometimes & $23(14)$ & $11(20.3)$ & .67 \\
\hline Rarely/Never & $7(4)$ & $4(7.4)$ & \\
\hline \multicolumn{4}{|l|}{ Feeding while on HHFNC, n (\%) } \\
\hline Strictly NBM & $5(3)$ & $6(11.1)$ & .018 \\
\hline May start NG/NJ feed & $108(69.5)$ & $24(46.2)$ & .002 \\
\hline May start oral feed & $17(10.3)$ & $12(22.2)$ & .02 \\
\hline \multicolumn{4}{|l|}{ Sedation ${ }^{d}, \mathrm{n}(\%)$} \\
\hline Never & $74(45.1)$ & $33(61.1)$ & .04 \\
\hline Rarely, sometimes & 65 (39.6) & $10(18.5)$ & .005 \\
\hline Most of the times & $3(1.8)$ & 0 & \\
\hline Always & 0 & 0 & \\
\hline
\end{tabular}

${ }^{\mathrm{a}} \mathrm{CPAP}$ on the ward and BLPAP on HDU, ${ }^{\mathrm{b}} \mathrm{CPAP}$ only, ${ }^{\mathrm{C}} \mathrm{HDU}$ only, ${ }^{\mathrm{d}} \mathrm{Chloral}$ hydrate was the most commonly used sedative, N/A Not applicable, NS Not significant

Respondents were asked to compare between CPAP and HHFNC on the wards, nearly two-thirds of them (67.9\%) said HHFNC is either the same or superior to CPAP with fewer complications (Table 4).
Clinicians were asked to rank their three most important outcome measures on the use of HHFNC therapy in any future research (Fig. 5). HHFNC Failure rate was the first most important concern amongst the respondents 


\begin{tabular}{|c|c|c|}
\hline Scenario & $\begin{array}{l}\text { 1- an infant }(<10 \mathrm{~kg}) \text { with moderate } \\
\text { respiratory distress: }\end{array}$ & $\begin{array}{l}\text { 2- } \\
\text { A child }(>10 \mathrm{~kg}) \text { with moderate } \\
\text { respiratory distress: }\end{array}$ \\
\hline $\begin{array}{l}\text { A: What is the } \\
\text { Start-up flow rate? }\end{array}$ & $\begin{array}{l}\text { Most respondents indicated a starting } \\
\text { flow rate for } \mathrm{HHFNC} \text { at } 2 \mathrm{~L} / \mathrm{kg} / \mathrm{min}(76.6 \%)\end{array}$ & $\begin{array}{l}68.9 \% \text { of the respondents said they would } \\
\text { start at } 2 \mathrm{~L} / \mathrm{kg} / \mathrm{min}\end{array}$ \\
\hline $\begin{array}{l}\text { B: What is the } \\
\text { HHFNC maximum } \\
\text { flow rate? }\end{array}$ & $\begin{array}{l}35 \% \text { of the respondents indicated keeping } \\
\text { the HHFNC flow rate at } 2 \mathrm{~L} / \mathrm{kg} / \mathrm{min} \text {, while } \\
\text { around } 40 \% \text { said they could go up to } 3-4 \\
\mathrm{~L} / \mathrm{kg} / \mathrm{min} \text {. }\end{array}$ & $\begin{array}{l}\text { Responses were almost equal (one third } \\
\text { each) in terms of either staying at } 2 \mathrm{~L} / \mathrm{kg} / \mathrm{min} \text {, } \\
\text { trying } 3 \mathrm{~L} / \mathrm{kg} / \mathrm{min} \text { or considering the } \\
\text { Manufacturer's recommendations if } \\
\text { available. }\end{array}$ \\
\hline $\begin{array}{r}\text { C: What is the } \\
\text { action plan if no } \\
\text { clinical } \\
\text { improvement while } \\
\text { on HHFNC? }\end{array}$ & $\begin{array}{l}\text { More than } 70 \% \text { said they will refer to the } \\
\text { intensive care/retrieval team for further } \\
\text { advice. }\end{array}$ & $\begin{array}{l}\text { More than } 70 \% \text { said they will discuss the case } \\
\text { with the intensive care/retrieval team for } \\
\text { further advice. }\end{array}$ \\
\hline Comments: & $\begin{array}{l}\text { A few respondents stated an } \\
\text { individualized protocol such as fixed flow } \\
\text { rate regardless of the weight, or a flow } \\
\text { range based on the weight (e.g. < 4kg: 5- } \\
8 \mathrm{~L} / \mathrm{min}, 4-10 \mathrm{Kg}: 8-12 \mathrm{~L} / \mathrm{min}) \text {. }\end{array}$ & $\begin{array}{l}\text { A few responses suggested an individualized } \\
\text { protocol starting at } 2 \mathrm{~L} / \mathrm{Kg} / \mathrm{min} \text { for the } 1^{\text {st }} 10 \mathrm{~kg} \\
\text { followed by } 0.5 \mathrm{~L} / \mathrm{kg} / \mathrm{min} \text { thereafter. }\end{array}$ \\
\hline
\end{tabular}

followed by the length of need for HHFNC support as second most important and cost-effectiveness as third (37.1, 28, and $28.8 \%$ respectively).

Overall, 187 clinicians (85.8\%) supported the idea of developing national guidance on the use of HHFNC in general paediatric practice. A small number of respondents said that such guidance is not necessary $(12 / 218$, $5.7 \%)$ and the remaining respondents were not sure if such guidelines might change current practice.

\section{Discussion}

This study is the first and the largest national survey to review the current practice around HHFNC on the paediatric wards in terms of the number of responses, the geographical areas that have been covered across the
UK and the use of HHFNC in many paediatric illnesses other than bronchiolitis, in addition to discussion about the supportive therapy while on HHFNC.

The study period was intentionally meant to span as many seasonal variations as possible to reflect practice and to minimize recall bias when HHFNC use is at its nadir in the summer.

In this survey, we noticed many areas of controversy and variation in clinical practice around HHFNC. As a non-invasive therapy, HHFNC is considered safe [18], easy to use and set-up for different age groups on the paediatric wards. When compared to LF oxygen therapy (maximum $\mathrm{FIO} 2$ of $40 \%$ ), higher oxygen concentration could be delivered and is well tolerated $[19,20]$. There is also some evidence that HHFNC in neonates and

Table 4 Respondents comparison between HHFNC and CPAP on the wards

\begin{tabular}{lllll}
\hline HHFNC & Efficacy $(\%, 95 \mathrm{Cl})$ & $p$-value & Complications (\%, 95Cl) & $P$-Value \\
\hline Superior to CPAP & $30.6(24.56-37.18)$ & $<.0001$ & $44.3(37.59-51.16)$ & $27.1(21.32-33.52)$ \\
Same as CPAP & $37.3(30.86-44.09)$ & $<.0001$ & $3.8(1.68-7.27)$ & $<.0001$ \\
Inferior to CPAP & $7.2(4.15-11.48)$ & $<.0001$ & $22.9(17.50-29.06)$ & $<.0001$ \\
I don't know & $19.1(14.11-24.96)$ & $<.0001$ & $<.0001$ \\
\hline
\end{tabular}




\section{Research priorities}

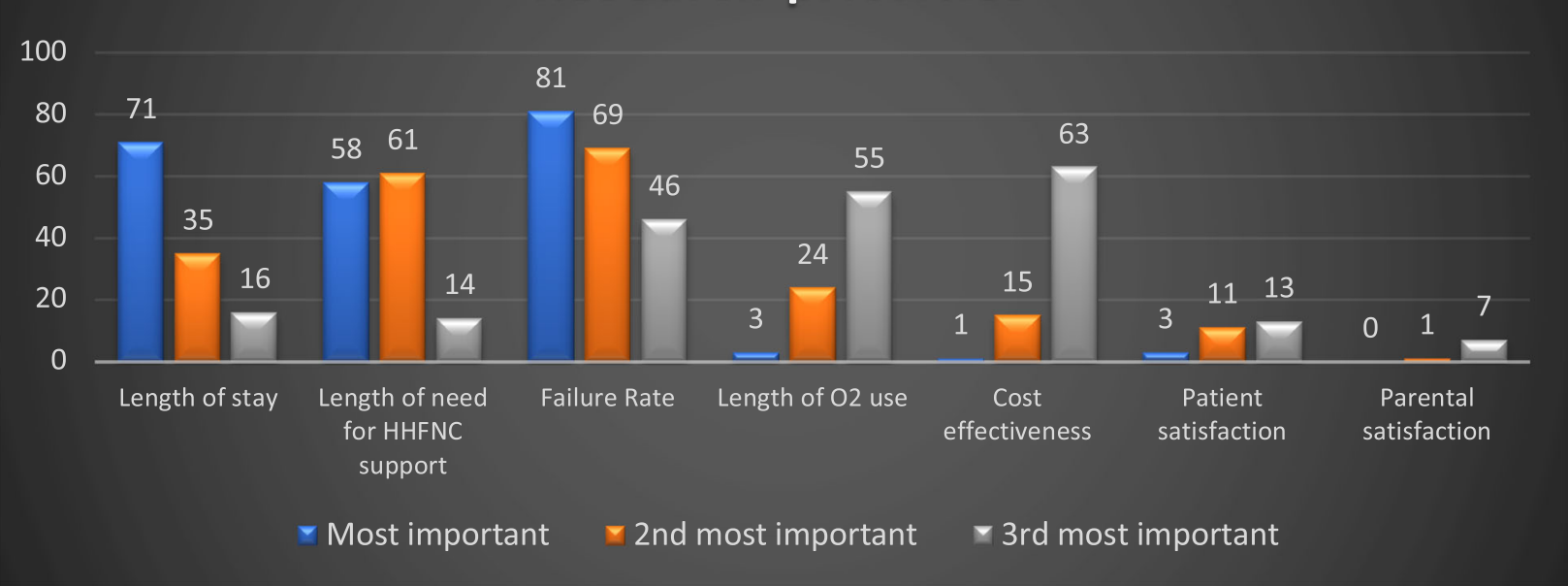

Fig. 5 Identified Research Priorities (numbers represent responses of total 218)

preterm babies is non-inferior to CPAP in preventing intubation and invasive ventilation [21, 22]. The reported literature is however limited when it comes to the use of HHFNC in the population beyond infancy and diseases other than bronchiolitis [23, 24]. Its role in avoiding intubation or as a step-down after extubation is yet to be tested [25]. Although the majority of the respondents have used HHFNC for patients with primary respiratory problems, others have also used it for patients with underlying cardiac (such as cardiac failure and postcardiac surgery) and neuromuscular-type diseases (Fig. 2) $[7,26,27]$.

Determining the initial HHFNC rate and the escalation strategy is still controversial as shown in this survey. While most respondents focused on $2 \mathrm{~L} / \mathrm{kg} / \mathrm{min}$ as a startup flow, others tried a range of $3-4 \mathrm{~L} / \mathrm{kg} / \mathrm{min}$ in cases of bronchiolitis and pneumonia. Using the actual patient's weight is a useful guide that most units have agreed on, however, it is worth mentioning though that most devices that deliver HHFNC are capped at $<2 \mathrm{~L} / \mathrm{kg} / \mathrm{min}$ for larger children with a maximum flow of $60 \mathrm{~L} / \mathrm{min}$. Majority of the surveyed units had criteria to determine HHFNC failure and an escalation strategy to an appropriate level of support demonstrated in the two case scenarios (Fig. 4).

Another area of controversy was the use of Aerosol therapy via HHFNC. The delivery of nebulized medicines is generally affected by flow, type of system used, cannula size, and type of nebulizer used [28]. Respondents didn't specify if certain nebulizing devices were used on their wards while connected to HHFNC.

Different feeding approaches were used for patients who were on HHFNC (oral, NG, NJ, NBM). It could not be ascertained, however, if oral feeding was only allowed in the weaning phase or administered throughout therapy. In general, keeping patients NBM while on HHFNC was the least favourable method as demonstrated in this survey (Table 3).

Nearly $80 \%$ of the respondents said they either never used sedation or used it sometimes for establishing HHFNC (Table 3).

HHFNC was generally assessed by $68 \%$ of our respondents to be either equal or more effective than CPAP with fewer complications [22]. Other surveys suggested similar results when HHFNC was particularly used in the neonatal age groups $[29,30]$. These results appear high considering the absence of randomised trial evidence of the effectiveness of HHFNC.

As a word of caution, this is a description of the current practice around HHFNC in the UK at the time the survey was conducted. We acknowledge that the total response rate in this survey is not large enough to make firm suggestions, however, we believe that this survey has served its purpose of highlighting the real need of further consolidated research and probably to work on developing a national guidance on the use of HHFNC on the paediatric wards similar to other countries [31].

\section{Conclusion}

HHFNC is a rapidly evolving therapy with little data that supports its benefit in many of the paediatric diseases that have been discussed in this survey. Our survey indicates that there is growing confidence amongst paediatricians around HHFNC that may justify its increasing use in children. The key research priorities that have been identified by our respondents may help guide 
future studies to answer these concerns and support their clinical decisions.

\section{Supplementary information}

Supplementary information accompanies this paper at https://doi.org/10. 1186/s12887-020-1998-1.

Additional file 1. Survey questionnaire.

\section{Abbreviations}

CPAP: Continuous positive airway pressure; FiO2: Fraction of inspired O2; HDU: High Dependency Unit; HHFNC: Heated Humidified High Flow Nasal Cannula; NBM: Nil Per Mouth; PICU: Paediatric Intensive Care Unit

\section{Acknowledgements}

The authors would like to thank all the retrieval services for their contribution to help distribute the survey to their local hospitals and in particular: Children's Acute Transport Service (CATS), Kids Intensive Care and Decision Support Service (KIDS), COMET (formerly, East Midlands Paediatric Transport Service), Southampton Oxford Retrieval Team (SORT).

\section{Authors' contributions}

$\mathrm{OH}$, designed the survey, carried out the data analyses, drafted the initial manuscript. CE helped designed, piloted, and distributed the survey. PR conceptualised the study, reviewed and revised the draft manuscript. All authors read and approved the final manuscript.

\section{Funding}

None.

\section{Availability of data and materials}

The datasets used and/or analysed during this study are available from the corresponding author on reasonable request.

\section{Ethics approval and consent to participate}

We confirm that this study complies with the national guidelines (HRA Decision Tool attached). Due to the nature of this study, completion of the survey was voluntary, and no ethical approval was required.

\section{Consent for publication}

Not applicable.

\section{Competing interests}

The authors declare that they have no competing interests.

\section{Author details}

${ }^{1}$ Paediatric Intensive Care Unit, Birmingham Children's Hospital, Birmingham Women's and Children's Hospital Foundation Trust, Steelhouse Lane, Birmingham B4 6NH, UK. 'Leeds Regional Paediatric Respiratory \& Cystic Fibrosis Centre, Leeds Children's Hospital, Leeds General Infirmary, Leeds, UK. ${ }^{3}$ Paediatric Intensive Care Unit, St Mary's Hospital, Imperial College Healthcare NHS Trust, London, UK. ${ }^{4}$ Children's Acute Transport Service, Great Ormond Street Hospital NHS Foundation Trust, London, UK.

Received: 6 December 2019 Accepted: 25 February 2020

Published online: 06 March 2020

\section{References}

1. Ramnarayan P, Schibler A. Glass half empty or half full? The story of highflow nasal cannula therapy in critically ill children. Intensive Care Med. 2017; 43(2):246-9.

2. Turnham H, Agbeko RS, Furness J, Pappachan J, Sutcliffe AG, Ramnarayan P. Non-invasive respiratory support for infants with bronchiolitis: a national survey of practice. BMC Pediatr. 2017;17(1):20.

3. Luo J, Duke T, Chisti MJ, Kepreotes E, Kalinowski V, Li J. Efficacy of HighFlow Nasal Cannula vs Standard Oxygen Therapy or Nasal Continuous Positive Airway Pressure in Children with Respiratory Distress: A MetaAnalysis. J Pediatr. 2019;215:199-208.e8.
4. Milesi C, Essouri S, Pouyau R, Liet JM, Afanetti M, Portefaix A, et al. High flow nasal cannula (HFNC) versus nasal continuous positive airway pressure (nCPAP) for the initial respiratory management of acute viral bronchiolitis in young infants: a multicenter randomized controlled trial (TRAMONTANE study). Intensive Care Med. 2017;43(2):209-16.

5. Modesto I, Alapont V, Pons Ódena M, Medina VA. Relying on objective data: the glass half empty of high-flow nasal cannula in bronchiolitis. Intensive Care Med. 2017;43(6):954-5.

6. Dysart K, Miller TL, Wolfson MR, Shaffer TH. Research in high flow therapy: mechanisms of action. Respir Med. 2009;103(10):1400-5.

7. Hutchings FA, Hilliard TN, Davis PJ. Heated humidified high-flow nasal cannula therapy in children. Arch Dis Child. 2015;100(6):571-5.

8. Ejiofor BD, Carroll RW, Bortcosh W, Kacmarek RM. PEEP Generated by HighFlow Nasal Cannula in a Pediatric Model. Respir Care. 2019;64(10):1240-49. https://doi.org/10.4187/respcare.06470.

9. Al-Subu AM, Hagen S, Eldridge M, Boriosi J. Aerosol therapy through high flow nasal cannula in pediatric patients. Expert Rev Respir Med. 2017;11(12):945-53.

10. Slain KN, Shein SL, Rotta AT. The use of high-flow nasal cannula in the pediatric emergency department. J Pediatr. 2017:93(Suppl 1):36-45.

11. Jones AJ, Mathew S, Wong SW, Patel M, Equi A, Sukhani S, et al. A regional audit of high-flow nasal cannula therapy use for bronchiolitis in London district general hospitals. Arch Dis Child. 2017;102(3):296-7.

12. Milesi C, Boubal M, Jacquot A, Baleine J, Durand S, Odena MP, et al. Highflow nasal cannula: recommendations for daily practice in pediatrics. Ann Intensive Care. 2014:4:29.

13. Mikalsen IB, Davis P, Oymar K. High flow nasal cannula in children: a literature review. Scandinavian J Trauma Resuscitation Emerg Med. 2016;24:93.

14. Badiee Z, Eshghi A, Mohammadizadeh M. High flow nasal cannula as a method for rapid weaning from nasal continuous positive airway pressure. Int J Prev Med. 2015:6:33.

15. Betters KA, Hebbar KB, McCracken C, Heitz D, Sparacino S, Petrillo T. A novel weaning protocol for high-flow nasal cannula in the PICU. Pediatr Crit Care Med. 2017;18(7):e274-e80.

16. Royal College of Paediatrics and Child Health. Medical Workforce Census 2015. London; 2017.

17. Royal College of Paediatrics and Child Health. High Dependency Care for Children - Time To Move On. London: Royal College of Paediatrics and Child Health; 2014

18. Roberts $C T$, Hodgson KA. Nasal high flow treatment in preterm infants. Matern Health Neonatol Perinatol. 2017;3:15.

19. Ward JJ. High-flow oxygen administration by nasal cannula for adult and perinatal patients. Respir Care. 2013;58(1):98-122.

20. Tiruvoipati R, Lewis D, Haji K, Botha J. High-flow nasal oxygen vs high-flow face mask: a randomized crossover trial in extubated patients. J Crit Care. 2010;25(3):463-8.

21. Manley BJ, Owen L, Doyle LW, Davis PG. High-flow nasal cannulae and nasal continuous positive airway pressure use in non-tertiary special care nurseries in Australia and New Zealand. J Paediatr Child Health. 2012;48(1):16-21.

22. Lavizzari A, Colnaghi M, Ciuffini F, et al. Heated, humidified high-flow nasal cannula vs nasal continuous positive airway pressure for respiratory distress syndrome of prematurity: a randomized clinical noninferiority trial. JAMA Pediatr. 2016. https://doi.org/10.1001/jamapediatrics.2016.1243.

23. Mikalsen IB, Davis P, Øymar K. High flow nasal cannula in children: literature review. Scand J Trauma Resusc Emerg Med. 2016;24:93.

24. Chisti MJ, Salam MA, Smith JH, Ahmed T, Pietroni MA, Shahunja KM, et al. Bubble continuous positive airway pressure for children with severe pneumonia and hypoxaemia in Bangladesh: an open, randomised controlled trial. Lancet (London, England). 2015;386(9998):1057-65.

25. Ramnarayan $\mathrm{P}$, Lister $\mathrm{P}$, Dominguez T, Habibi $\mathrm{P}$, Edmonds N, Canter RR, et al. FIRST-line support for Assistance in Breathing in Children (FIRST-ABC): a multicentre pilot randomised controlled trial of high-flow nasal cannula therapy versus continuous positive airway pressure in paediatric critical care. Crit Care (London, England). 2018;22(1):144.

26. Carratala JM, Diaz Lobato S, Brouzet B, Mas-Serrano P, Espinosa B, Llorens P. Efficacy and safety of high-flow nasal cannula oxygen therapy in patients with acute heart failure. Emergencias. 2018:30(6):395-9.

27. Testa G, lodice F, Ricci Z, Vitale V, De Razza F, Haiberger R, et al. Comparative evaluation of high-flow nasal cannula and conventional oxygen therapy in paediatric cardiac surgical patients: a randomized controlled trial. Interact Cardiovasc Thorac Surg. 2014;19(3):456-61.

28. Berlinski A. Pediatric aerosol therapy. Respir Care. 2017;62(6):662-77. 
29. Ojha S, Gridley E, Dorling J. Use of heated humidified high-flow nasal cannula oxygen in neonates: a UK wide survey. Acta paediatrica (Oslo, Norway : 1992). 2013;102(3):249-53.

30. Hough JL, Shearman AD, Jardine LA, Davies MW. Humidified high flow nasal cannulae: current practice in Australasian nurseries, a survey. J Paediatr Child Health. 2012;48(2):106-13.

31. Chauvin-Kimoff L, DeCaen A. Use of high-flow nasal cannula oxygen therapy in infants and children. Paediatr Child Health. 2018;23(8):555. https://doi.org/10.1093/pch/pxy142.

\section{Publisher's Note}

Springer Nature remains neutral with regard to jurisdictional claims in published maps and institutional affiliations.

Ready to submit your research? Choose BMC and benefit from:

- fast, convenient online submission

- thorough peer review by experienced researchers in your field

- rapid publication on acceptance

- support for research data, including large and complex data types

- gold Open Access which fosters wider collaboration and increased citations

- maximum visibility for your research: over $100 \mathrm{M}$ website views per year

At BMC, research is always in progress.

Learn more biomedcentral.com/submissions 